\title{
FRAY JUAN RAMIREZ, LOS INDIOS Y LA GUATEMALA DEL SIGLO XVII
}

Mario Humberto Ruz

Centro de Estudios Mayas

No dudo que por decir la verdad... he de ser odiado y aborrecido, y como esto es general contra todos los que la dicen, no me da mucha pena; que no faltará quien vuelva por ello (que es lo que me consuela), y aún por mí.

Fray Juan Ramírez,

Relación de agravios a los indios. Año de 1604

\section{Introducción}

En el estudio de la historia hay épocas cuya riqueza cultural o los enigmas de su desarrollo parecen fascinar a los investigadores. En lo que respecta a las etnias mayanses, la época prehispánica ha sido privilegiada; la magnificencia de las creaciones culturales mayas clá. sicas y las interrogantes que su declinar plantea, han dado origen a una abundante y disimil literatura. No fue sino hasta fechas relativamente recientes cuando los estudiosos comenzaron a interesarse en los herederos de tal grandeza, los mayas contemporáneos, en muchos casos intentando legitimar el "precario" estado cultural en que ha devenido tal herencia o, intento no menos parcial y en cierta medida objetable, con el interés de explicar aspectos hasta ahora oscuros de los primeros a partir de los segundos.

$\mathrm{Al}$ apuntar "en cierta medida objetable", no pretendo de ninguna manera invalidar la pertinencia de tales intentos. Mi objeción se sitúa en los linderos de la metodología empleada: unir dos momentos históricos ignorando el puente cronológico que los comunica. En efecto, participando de una actitud por desgracia frecuente entre los 
investigadores de la historia mexicana, el estudio de los mayas que vivieron bajo el dominio español ha sido, como su época, soslayado. Como señalara con atino Octavio Paz, "vivimos entre el mito y la negación, deificamos a ciertos periodos, olvidamos a otros... Nuestra historia es un texto lleno de pasajes en tinta negra y otros escritos en tinta invisible". ${ }^{1}$ La historia de los mayas coloniales parece escrita con la segunda; pero sólo lo parece. Las archivadas voces de estos indígenas esperan el momento en que una época revalorizadora les haga objeto de investigaciones-sonidos para transmitirnos su mensaje; un mensaje pleno de denuncias y rico en testimonios que dan buena cuenta de estrategias de supervivencia, adaptaciones culturales y luchas no tan silenciosas emprendidas para permanecer. Por ello, si intentar comprender y explicar a los mayas prehispánicos a través de las etnias actuales es un intento válido, hacerlo ignorando el culturalmente convulso y gestador mundo colonial es caer, mínimamente, en actitudes ahistóricas.

Cierto es que existen estudios sobre tal época, pero éstos se antojan escasos cuando se vislumbra la importancia del momento. Por otra parte, y correspondiendo otra vez al mito nacionalista, la mayoría de las investigaciones se ha centrado en los grupos nahuas y las zonas por ellos ocupadas. La pobreza de trabajos sobre el área maya es significativa y decepcionante. Y la mayoría de estudios con. cienzudos para tal zona la debemos a investigadores extranjeros.

Fascinados - y atrapados - ante un mundo de cosmovisiones prehispánicas y carnavales contemporáneos, se nos han ido olvidando los mayas que, manteniendo el recuerdo de las unas pudieron sustentar, readaptándolo, el simbolismo implícito en la celebración de los otros.

En la mayoría de los casos son testimonios indirectos los que han llegado hasta nosotros. En una época en que el único valor que se asignaba al indígena maya era su fuerza de trabajo, poco tiempo e interés hubieron para alentar la transcripción de sus vivencias históricas. Pero los naturales no se encontraron solos en su intento de permanencia; otras voces se elevaron por ellos y otras plumas se encargaron de consignar la secular fortaleza de tal intento.

En la región que comprendía la Capitanía General de Guatemala, y durante los dos primeros siglos de la Colonia, buena parte de estas funciones testimoniales corrieron a cargo de los frailes dominicos, y baste citar entre ellos a fray Bartolomé de Las Casas, fray Tomás

1 Paz, 1982: 23. 
de La Torre, fray Agustín Cano, fray Domingo de Ara, fray Antonio de Remesal y otros cuyos escritos se han perdido o han pasado a formar parte de esa conciencia histórica que hasta hoy permanece archivada, contribuyendo así a mantener el vacío de información sobre los mayas coloniales que posibilitara la cabal comprensión de los mayas contemporáneos.

Intentando ayudar a suplir este vacío, el Centro de Estudios Mayas decidió impulsar las investigaciones concernientes a la época colonial. Gracias a ello cuenta hoy con un rico acervo documental que ha permitido iniciar diversos estudios sobre la vida de los mayas bajo el dominio español. Como parte del programa destinado a reunir tales materiales se efectuó una investigación en el Archivo Secreto Vaticano, gracias a la cual pudimos obtener fotocopias y microfilmes de documentos en su mayoría inéditos. Entre ellos se encuentran los testimonios que hoy presento.

\section{Fray Juan Ramírez: notas biográficas}

A pesar de su destacado papel como defensor de los indios, poco se ha escrito sobre fray Juan Ramírez, cuarto obispo de Guatemala. ${ }^{2}$ Como ocurre en otros casos, la figura del dominico fue en cierta medida relegada ante la señera estatura de fray Bartolomé de Las Casas, el defensor por antonomasia. Sin embargo, el estudio de su obra nos provee de abundantes datos que, a diferencia de su hermano en la religión, emergen como resultado de una acción directa y continua como cabeza de su diócesis, pues estuvo al frente de ella durante un largo periodo (1601-1609) y -lo que no ocurrió con el obispo chiapaneco- la visitó en diversas ocasiones procurándose información de primera mano. ${ }^{3}$

Sabemos que Juan Ramírez de Arellano, descendiente de la nobleza de Aragón, era natural de la Rioja, de la villa de Morillo. Empero, ninguno de sus biógrafos (casi todos ellos repetidores de Remesal) proporciona la fecha de su nacimiento.*

2 Dos trabajos actuales sobre el prelado son un artículo de Sherman (1968), y otro de Benno Biermann titulado "Don Fray Juan Ramírez de Arellano, O.P. und sein Kampf gegen die Unterdrückung der Indianer", Jahrbuchfur Geschichte von Staat, Wirtschaft und Gesellschaft Lateinamerikas IV, p. 318-347, Berlin, 1967. Este último, por desgracia, no me fue posible localizarlo.

3 Fray Bartolomé sólo permaneció poco más de un año en su obispado y las visitas que practicó a los pueblos del mismo fueron mínimas.

4 Los datos de Remasal (1966, IV: 1857-75), ligeramente enriquecidos por 
Profesó como dominico en el convento de Logroño, realizando estudios superiores en el convento de Salamanca ${ }^{5}$ donde destacó en forma particular en teología. ${ }^{6}$ Tras escuchar la plática de un religioso venido de la Nueva España en busca de frailes para la provincia de México, decidió emprender el viaje. Al llegar fue asignado a la Mixteca, donde, según Remesal, aprendió la lengua en tres meses y se destacó en la predicación. ${ }^{7}$ Después de un Capítulo celebrado en Yanhuitlán, donde pudieron apreciar sus dotes académicas, decidieron sus superiores trasladarlo al convento de México, donde fungiría como lector de Artes. Finalmente impartió la cátedra de Teología Moral, cargo en el que duró catorce años a decir de Ximénez, y veinticuatro según Remesal y Juarros. ${ }^{8}$

El poco tiempo que sus labores como maestro de teología y calificador del Santo Oficio le dejaban, lo dedicó con particular empeño a adoctrinar a los negros y mulatos, a quienes consideraba los fieles más abandonados. ${ }^{\ominus}$ En esta labor se señaló por su humildad, virtud que le atribuyen todos sus biógrafos, y que no corrompieron ni los cargos de presentado y subprior que detentó en el convento de México, ni la posterior mitra.

Desde un inicio comenzó a perfilarse la que sería su gran preocupación como obispo: la situación laboral indígena. Así, dedicóse a estudiar en forma detenida el pago de jornales, las características del repartimiento y otras formas de trabajo forzoso. Envió luego su parecer escrito al Sínodo de México (¿1585?) el cual, tras prometer estudiarlo, lo archivó, no sin encargar antes al religioso que no tratase públicamente la materia. Su respuesta fue inmediata: en el primer sermón que pudo pronunciar en la catedral metropolitana, arremetió contra el injusto sistema laboral, lo que le valió una suspensión de la licencia para predicar. ${ }^{10}$

Al igual que Las Casas, se negaba a absolver a quien tuviese indios de repartimiento si no prometía dejarlos libres, y convencido asimismo de que el remedio a las vejaciones que sufrían los indí-

Ximénez en lo referente a las supuestas intervenciones milagrosas del obispo, constituyen - con pocas variantes- la fuente de los estudios más recientes.

5 Remesal, ob. cit.: 1857.

6 Gavarrete, 1980:37.

7 Remesal, ob. cit., 1858.

8 Remesal, ibid.; Estrada, 1973:199; Juarros, 1981:152, Ximénez; 1930: 36.

9 Remesal, ob. cit.: 1859; Rodríguez Cabal, 1961:147.

10 Remesal, ob. cit.: 1863. 
genas sólo podría alcanzarlo abogando directamente en la Corte, decidió viajar a España después de realizar una visita en toda la provincia de México para enterarse de la situación laboral existente. ${ }^{11}$

El viaje a Veracruz, como sería su costumbre, lo emprendió a pie, llevando por todo equipaje su capa y un breviario y por único caudal una cédula de noventa y cinco pesos pagadera en Sevilla. Buscando flota pasó a Campeche y de ahí a La Habana, donde al fin pudo embarcarse en un navío de aviso que durante el trayecto fue abordado por corsarios ingleses. Así, en lugar de la corte de Madrid, nuestro fraile fue a parar a una prisión de Inglaterra, de donde se le liberó después de prometer que intercedería por la suerte de un caballero inglés preso en Sevilla. ${ }^{12}$

Tras obtener del superior de la Orden, fray Hipólito María, la promulgación de una serie de censuras contra los religiosos que utilizaban indios de repartimiento, paś́ a Madrid, donde permaneció cuatro años. Durante ellos redactó dos memoriales que fueron impresos, el uno titulado Advertencias del padre..., Maestro en Sacra Teologíc, sobre el servicio personal al cual son forzados y compelidos los indios de la Nueva España por los visorreyes que en nombre de Su Majestad los gobiernan, y el otro, Parecer del padre Maestro..., de la Orden de Predicadores de Santo Domingo, sobre el servicio personal y repartimiento de los indios, dado al Consejo Real de Indias, ambos fechados en Madrid en octubre de 1595, y firmados por diversas personalidades dominicas de la época. ${ }^{13}$

A punto de regresar a América, el 18 de enero de 1600, fue presentado para ocupar el obispado vacante de Guatemala. Después de aceptar por orden de sus superiores, fue confirmado por la Santa Sede el 12 de mayo de $1600 .{ }^{14}$ Deseando aprovechar el año de jubileo que entonces se celebraba emprendió a pie el viaje a Roma, donde rindió homenaje a Clemente VIII el 28 de diciembre. ${ }^{15}$ Durante el regreso a España unos bandoleros de Cataluña le despoja-

11 Remesal, ob. cit.: 1864, 1866; Gavarrete, ob. cit.: 37.

12 Remesal, ob. cit.: 1867; Ximénez, ob cit.: 40; Juarros, ob. cit.: 152.

13 Archivio Segreto Vaticano, Segretaria Stato, Nunziature Diverse 264, f 37-42. Sobre los nombres e importantes cargos de los firmantes, véase Remesal, ob cit.: 1868.

14 Archivio Segreto Vaticano, Acta Camerarii, v 13, f 140; SchmitzKallenberg, 1923, v III: 207 y v IV: 199.

15 Archivio Segreto Vaticano, Visitas ad Liminam, Guatemala, f1. 
ron de su pectoral y anillo ("que lo uno y lo otro eran de harto poco precio")..$^{16}$

Aunque sus biógrafos anotan que le consagró en Madrid el obispo de Córdoba, don Pablo de Laguna, ${ }^{17}$ existe una misiva en el Archivo Vaticano donde declara haber sido consagrado el 20 de julio de 1600 por el arzobispo Lipontin, nuncio apostólico, asistido por el obispo Joan González de Mendoza y el diocesano de Puerto Rico, don Martín Vázquez de Arce. ${ }^{18}$

En febrero de 1601 se encontraba en La Habana esperando un barco para dirigirse a Honduras. Permaneció en Cuba hasta agosto, y el 9 de ese mes escribió al ayuntamiento de Santiago que se encontraba en Trujillo, pronto para entrar a la capital. Tal hizo el 25 de octubre. ${ }^{10}$

Su actuación al frente del obispado es caracterizada por sus biógrafos como pacífica, caritativa y muy edificante por su devoción, humildad y pobreza. ${ }^{20}$ Pero parece que no lo fue tanto en lo que al clima de paz respecta; además de sus continuas dificultades con el Cabildo, que motivaron el que se quejara a Roma (vid infra), tuvo serios problemas con el presidente de la Audiencia, los oidores y el Ayuntamiento. Tales problemas, que por tradición se adjudican a su exigencia de interrogarles sobre la doctrina cristiana durante los oficios en la catedral, ${ }^{21}$ parecen estar más bien relacionados con su actitud respecto al trato que los gobernantes otorgaban a los indígenas.

Apenas a un año de llegado a su sede, el Ayuntamiento solicitaba, junto con la anexión del obispado de Verapaz al de Guatemala y la constitución de este último en metropolitano, que se nombrara arzobispo a don Juan Fernández de Rosillo (obispo de Verapaz nominado para Michoacán), trasladándose a Ramírez a la sede de Valladolid "o a otra parte donde sirviese a Dios Nuestro Señor sin las inquietudes que ha tenido desde que vino a esta tierra". ${ }^{22}$

16 Remesal, ob. cit.: 1870.

17 Estrada, ob. cit.:201; Rodríguez Cabal, ob. cit.: 147; Gavarrete, ob. cit.: 38.

18 Archivio Segreto Vaticano, Visitas ad Liminam, Guatemala, "Lettera de fray Joannes Ramirez, O.P. Romae, 19-I-1601", f 1.

19 Rodríguez Cabal, ob. cit: 147; Estrada, ob. cit.: 201.

20 Remesal, ob. cit.: 1870-73; Ximénez, ob. cit.: 43ss; Juarros, ob. cit.: 152; Rodríguez Cabal, ob. cit.: 147; Vázquez, 1944: 368, 378, 379.

21 Milla, 1963; 220-21; Juarros, ob. cit.: 152.

22 Carta del Ayuntamiento de Santiago de Los Caballeros fechada el 
Tales "inquietudes" seguramente corresponden a las quejas que fray Juan elevaba en forma continua al rey sobre las vejaciones que las autoridades infligían a $l o s$ indios, ${ }^{23}$ mismas que pudo comprobar durante las visitas que efectuó en toda su extensa diócesis y de las que por desgracia sólo algunas relaciones han llegado hasta nostros. ${ }^{24}$

La situación con la Audiencia y el Ayuntamiento se hizo tan tirante, que el obispo tuvo que abandonar la sede episcopal e irse a refugiar a la ciudad de San Salvador, donde murió el 24 de marzo de $1609,{ }^{25}$ siendo enterrado no en el convento de Santo Domingo, como él solicitara, sino en la iglesia mayor, de donde se le traslado (a mediados de siglo) a la capilla mayor del nuevo templo salvadoreño. Ni siquiera allí encontró reposo: en 1717 sus restos fueron robados, ignorándose su actual ubicación. Sólo su sombrero, reputado por los naturales como milagroso, continuaba para tales fechas circulando entre los pueblos indígenas a la manera de efectivo mediador del favor divino. ${ }^{26}$

\section{Los documentos}

Aunque Juarros reduce la producción literaria de fray Juan a "una obrita que intituló Campo Florido", ${ }^{27}$ ésta fue mucho mayor. Además de su correspondencia, abundante en número y rica en datos, el obispo nos legó, amén de los dos textos de 1595, los siguientes escritos:

2 de mayo de 1602 (En Milla, ob. cit.: 200). Aunque MacLeod (1976:33) apunta que para zanjar las dificultades la Corona accedió a trasladar a Ramírez a Michoacán, tal traslado nunca ocurrió.

La Verapaz fue anexada al obispado de Guatemala por Real Cédula del 23 de junio de 1608, la constitución de Guatemala en arzobispado no se conseguiría, en cambio, sino hasta el 16 de diciembre de 1743 (Estrada, ob. cit.: 44,202 ).

${ }^{23}$ Sobre la abundante correspondencia del obispo con la Corona y el Consejo, véase Sherman, ob. cit.: 5-8.

24 Sherman, Ibid; Estrada, ob. cit: 201; Carrasco, 1982: 155.

25 Remesal, ob. cit.: 1874; Milla, ob. cit.: 221. Estrada (ob. cit.: 202), anota que Ramírez se encontraba efectuando una visita pastoral en Salvador cuando le sorprendió la muerte, pero en el resto de sus biógrafos resulta claro que el obispo se había ya exiliado voluntariamente en esta ciudad.

26 Ximénez, ob. cit.: 47-48. Sobre dos hechos milagrosos atribuidos al prelado véase este mismo autor en las páginas 39 a 47 , y Gavarrete, ob. cit.: 54.

27 Juarros, ob. cit.: 152. Sobre la utilización de esta obra con fines evangelizadores, véase Arróniz (1979:135). 
- Vida, virtudes y muerte del Venerable fray Enrique Susón,

- Crónica de los varones ilustres de la Orden de Santo Domingo,

- Campo Florido: ejemplo de santos para exhortar a la virtud con su invitación y ejemplo. Dedicado al Ilustrísimo Señor don Pedro de Feria, obispo de Chiapa (impreso en 1580 y reimpreso en Madrid en 1658, bajo el título Albor ae las Virtudes),

- Secundus tomus adnotationum in $2^{a}$ 2ae. S. Thomae a quest. 67 ad finem (1575),

- Relación cierta de agravios que reciben los naturales de las provincias distantes de Guatemala, y

- Dictamen sobre el servicio personal de los indios. ${ }^{2 \mathrm{~s}}$

$\mathrm{Si}$ bien los textos de 1595 sobre el servicio personal han sido reeditados por Estrada, mientras que Sherman se encargó de estudiar una parte de la correspondencia del obispo, ${ }^{29}$ los escritos que dirigió a la Santa Sede permanecen aún inéditos. Consisten en tres cartas fechadas entre febrero y marzo de 1606 (en español y latín), ${ }^{30}$ un informe sobre el repartimiento (1601) y diversas notas en latín e italiano sobre la Visita ad Limina. ${ }^{31}$ Estos documentos se caracterizan no sólo por la riqueza de datos que aportan sobre la Guatemala de inicios del siglo xvIr, sino también por su carácter de denuncia contra la explotación indígena. Trataremos aquí de las cartas y el informe, localizados en las secciones Visitas ad Limina, Guatemala, f 219-223 y Segretaria Stato, Nunziature. Diverse 264, f 36-73, respectivamente.

La primera de las cartas, dirigida a Clemente VIII (1592-1605), cuya muerte al parecer no era aún conocida en Guatemala, la inicia el prelado reiterando su obediencia al pontífice y disculpándose

28 Rodríguez Cabal, ob. cit.: 147-48; Gavarrete, ob. cit.: 55.

29 Los impresos fueron reproducidos por Estrada, ob. cit: : 203-219. La correspondencia, como ya señalé, sirvió a Sherman para el artículo aparecido en 1968.

30 Algunas cartas presentan más de una fecha inserta en el texto o en los márgenes. La que está foliada primero (f 219) es la más tardía, pues se fecha el catorce de marzo, mientras que las otras dos son de febrero. Se citan modernizando la ortografía. Agradezco a Bulmaro Reyes la ayuda que me proporcionó en la lectura de algunos textos en latín.

${ }^{31} \mathrm{La}$ Visita ad Limina era la obligación que tenían los obispos de visitar en forma periódica las tumbas de los apóstoles Pedro y Pablo, localizadas en las basílicas romanas de San Pedro y San Pablo extramuros. En el caso de los prelados americanos tal visita debía efectuarse una vez cada diez años, existiendo la posibilidad de obtener una prórroga por otros diez años. Debe destacarse que por lo general los obispos del Nuevo Mundo usaron del privilegio de enviar a un procurador en su nombre. 
de no poder asistir personalmente a hacerlo "por la grande distancia que hay, y estar en medio ese grande mar Océano que tiene de travesía para España más de dos mil leguas, demás de las que hay por tierra del lugar donde estamos a España, y de España a Roma". Informa que en 1602 envió a un cura beneficiado de su catedral con cartas para el pontífice, pero aquél, "por su mucha pusilanimidad, temiendo donde no había que temer", no se atrevió a ir y envió por otro medio las cartas, que de seguro fueron "a mal recaudo y ansí no hubieron efecto". ${ }^{32}$

El obispado, apunta, tiene tres ciudades: Santiago, San Salvador y San Miguel, y dos villas: los de La Trinidad y Jerez de la Choluteca. En la catedral hay cinco dignidades y cinco canónigos, además de algunos capellanes en lugar de racioneros. "Cuando vacan algunas destas canongías o dignidades, los que asisten reparten entre sí todas las prebendas vacantes; habiéndose de dar a la fábrica, las aplican para sí los prebendados diciendo que hay costumbre de ello", situación que Roma debe ordenar se suspenda pues la fábrica de la catedral, que está muy pobre, requiere con urgencia de tales prebendas.

De las iglesias de españoles se recolecta un total de 45,000 tostones en diezmos, y de ellos "dánse a los beneficiados de San Salvador, San Miguel y Chuluteca a doscientos tostones, y a las fábricas destas iglesias se dan cincuenta cada año. Todo lo demás se reparte entre los prebendados y capellanes y también lleva su parte el rey por ser patrón, ${ }^{33}$ y alguna parte también se da a los pobres". Reporta que existen 175 partidos en la diócesis, que se dividen entre clérigos, dominicos, franciscanos (cincuenta partidos cada uno) y mercedarios. Aquellos que están a cargo de estos últimos

Apenas llegarán a veinticinco, en tierras muy remotas, pobres y trabajosas [el actual departamento de Huehuetenango] y aún peligrosas, por estar cercanas y finítimas a indios infieles que lla-

32 Tales cartas, como suponía el obispo, parecen no haber llegado a su destino; al menos no constan en la sección correspondiente del Archivo: Lettere de Vescovi e prelati.

3s Se refiere al Real Patronazgo sobre las iglesias de América concedido por el Papado a los monarcas de Portugal y España. Gracias a éste, los reyes disponían del derecho de proponer y presentar personas para todos los oficios eclesiásticos en las misiones y diócesis ultramarinas. A cambio de encargarse de la evangelización y resguardo de la fe, disfrutaban además te parte de los diezmos (dos novenos). 
man lacandones y mastreses [mancheses] que no están convertidos a la fe y son infestuosos a los recién convertidos. Muchos son caribes y comen carne humana; no tienen religión alguna. No se sabe el número de la gente que son, por ser su tierra pobre y no han entrado en ella los españoles.

La diferencia de tales indígenas que habitaban las fronteras de la colonización con los ya sometidos, la establece por supuesto en aspectos atribuibles a la evangelización. Así anota que estos últimos, bien doctrinados y asiduos a los sacramentos, ${ }^{34}$ son obedientes, sufridos, cooperadores, más devotos que los españoles, sin "rastro ni vestigio ni apariencia de idolatría", humildes, pacientes y "amicísimos de las ceremonias eclesiásticas", lo que le hace exclamar: "según nuestro parecer, todos los indios a una mano parece que son la gente más apta para el Cielo de cuantas gentes hay en la Tierra".

Comentario especial le merece la aptitud musical de los naturales, extraordinariamente dotados para el canto llano y de órgano, así como para la ejecución de instrumentos, pues "mejor que en la catedral de Guatemala tienen sus flautas y ministriles, sacabuches y chirimías". Por todo ello, propone una medida que sin duda hubo de escandalizar al clero peninsular y criollo: ordenar al menos cinco o seis naturales por pueblo "y darles la prima tonsura, para que fuesen clérigos conjugados y que, con alguna señal de hábito clerical, se diferenciasen de los otros indios". Ello tendría además la ventaja de sustraer a tales indígenas de la jurisdicción civil,

porque reciben de los jueces seculares muchos y muy graves agravios, y como son ellos los maestros que enseñan a los otros la doctrina y cantan en la iglesia y hacen todo lo que los canónigos, excepto el decir misa, es grande inconveniente que los jueces seculares los castiguen y los ofendan en público por defectos muy pequeños, sin tenerles respeto alguno...

Preocupado por la dificultad de administrar una diócesis tan vasta $\sin$ suficiente autonomía y sobre todo tan alejada de la cabecera (el arzobispado de México), propone que los obispados de Nicaragua, distante más de mil leguas por mar de Perú, de donde

s4 El obispo anota: "hémosles dado licencia para comulgar, porque realmente son capaces de todos los sacramentos". Es de destacar también que se le atribuyen más de 90,000 confirmaciones durante su obispado (Sherman, ob. cit.: 8 ). 
dependía; Comayagua, que requería de un largo y riesgoso viaje para acceder a La Española; Chiapas, Verapaz y Guatemala, a más de trescientas leguas de México, se constituyan en un arzobispado independiente, quedando Santiago como iglesia metropolitana; cabecera eclesiástica "como ya lo es en lo civil, para los cinco obispados".

La última parte de esta primera carta trata de uno de los principales problemas que, como tantos otros obispos celosos de su deber, hubo de enfrentar nuestro prelado: la intromisión que los funcionarios civiles hacían en asuntos eclesiásticos, usando de las prerrogativas del Real Patronato. Dada la precisión de los datos, he decidido transcribirla en su mayor parte. Reza así:

En cuanto a la jurisdicción eclesiástica en esta tierra, está muy aniquilada, porque por la licencia que dicen tener el presidente y oidores de la Audiencia Real para quitar las fuerzas que hacen o pueden hacer los jueces eclesiásticos, se entremeten en todo. $\mathrm{Y}$ por frívolas que sean las apelaciones para el metropolitano si acuden, como acuden todos cuantos apelan a la Audiencia Real por vía de fuerza, luego la Audiencia declara que no conceder [sic] la apelación. Al obispo hace fuerza y compele con grandes penas de las temporalidades y extrañeza del reino, ${ }^{35}$ a que conceda la apelación, por frívola que sea, sin tener respeto alguno a lo decretado en el Concilio Tridentino, sesión 13, capítulo $1^{\circ}$, De Reformatione Cum Igitu Rei Criminum, ni tampoco a lo decretado en la sesión 24, capítulo 10.

Es tanta la insolencia de estos jueces seculares, que no sola. mente compelen al obispo y juez eclesiástico a conceder la apelación, sino que le mandan exhibir los autos, haciéndose ellos jueces y censores de todos los procesos y autos que pasan ante el juez eclesiástico. Y pasa más adelante su osadía y atrevimiento, que le mandan reponer todo cuanto ha hecho, y que absuelva a los que ha descomulgado, contra lo decretado en la sesión 25, capítulo 3 del Concilio Tridentino... y contra la bula In Coena Domini ${ }^{36}$ en la cual se prohibe lo mismo a los jueces seculares, y sub pretextie prohibende violenciae, todos estos lugares los tie-

s5 Tales medidas trataron de aplicarse ochenta años después en la persona del no menos belicoso obispo de Chiapas, don fray Francisco Núñez de la Vega (véase el estudio introductorio a la obra de este autor. En prensa).

3o Esta bula, promulgada por Sixto $\mathrm{V}$ en 1585 y ratificada por varios de sus sucesores, ennumera diversos actos contra la religión y los creyentes, que eran merecedores de excomunión y anatema; entre ellos, la intromisión de autoridades civiles en materias eclesiásticas, caso al que se refiere Ramírez. El texto completo de la bula consta en uno de los apéndices de la obra de fray Francisco Núñez (en prensa). 
nen atropellados y atropillan a cada paso y no hacen dellos caso alguno, y el capítulo 20 de la sesión 25 es tan hollado dellos como si el Concilio no lo hubiera puesto...

La ingerencia había alcanzado límites tales, que los funcionarios intentaban reglamentar incluso actividades litúrgicas. Así, exigían que se les rindiesen honores especiales durante los servicios religiosos, que se les diese la comunión antes que al propio clero $y$, lo que provocó el escándalo del pueblo y la cólera del obispo, prohibieran que el capellán levantase la capa del prelado mientras éste dirigía las procesiones, para evitar que se enlodase. Este tipo de detalles, en apariencia banales, nos da una idea de la rivalidad existente entre los dos poderes; rivalidad que no era exclusiva, por supuesto, de la Capitanía de Guatemala. Harto conocidas son las pugnas que por disfrutar de determinados honores se entablaron entre la corte virreinal y los miembros del Santo Oficio.

La carta termina con una súplica al papa que, de haber sido conocida por la Corona, sin duda hubiera acarreado no pocos problemas al obispo, a quien, como sabemos, le estaba terminanten:cnte prohibido emitir juicios que atentasen contra el Real Pa. tronato: ${ }^{37}$

Conviene en todo caso que Vuestra Santidad, pues es vicario supremo de Cristo, supra omnes príncipes seculares, acabe de concluir el pleito que se trata en Roma sobre quitar a los reyes el conocer de fuerzas que hagan los jueces eclesiásticos... y por lo menos que se coarte y limite esta tan ampla [sic] autoridad... [pues] desta manera va todo inverso, contra toda razón y derecho. Nuestro Señor de a Vuestra Santidad la fortaleza que se requiere para atajar estos y otros muchos inconvenientes que van introduciendo los jueces seculares, usurpando para sí tocia la jurisdicción eclesiástica.

La segunda carta, fechada un día después de la anterior, la dedica a narrar los problemas que ha tenido con el dean y Cabildo catedralicios. Aunque menos rica en datos sobre el obispado, re-

37 Antes de otorgar a los obispos y arzobispos destinados a las Indias sus presentaciones o ejecutorias, se le hacía jurar, "solemne/mente/ por ante escribano público y testigos, de no contravenir en tiempo alguno ni por ninguna manera a nuestro Patronazgo Real, y que le guardarían y cumplirían en todo y por todo, como en él se contiene, llanamente y sin impedimento alguno..." (ley 18, Título VII, Libro I de la Recopilación de Leyes de Indias). A quienes no llevasen una certificación de haber hecho tal juramento, no se les daría posesión. 
sulta de interés para observar la evolución de disputas que, inicián. dose como desacuerdos de tipo litúrgico, podían llegar a desembocar en verdaderos alegatos teológicos.

El caso mencionado por Ramírez tuvo sus raíces en una disposición de su predecesor, don Fernando Gómez de Córdoba (obispo de 1574 a 1598), el cual, por problemas con el calendario litúrgico, celebró en una ocasión con mayor pompa el 8 de agosto que el resto de los días de la infraoctava de la Asunción. Basándose en ello, el Cabildo, mientras duró la sede vacante, continuó celebrando la fiesta en diversas fechas. Además, habían ideado una verdadera escenografía para conmemorar el hecho: mantenían durante algunos días una imagen de la Virgen en un ataúd, y después, por medio de curiosos "efectos especiales", izaban otra imagen parecida simulando la asunción.

El prelado, además de estar en desacuerdo con lo que se le antojaba una pantomima irreverente, sostenía que la variación de fechas confundía a los fieles haciéndoles creer que el alma de la Virgen había permanecido separada de su cuerpo un tiempo diferente del que marcaba la tradición cristiana. Así pues, la disputa se centró en si la asunción se había verificado tres, cuatro, ocho o cuarenta días después de la dormición de María. Al Cabildo unióse el metropolitano ("que no ve la malicia"), quien respondió al obispo que si no estaba conforme con su opinión le turnase el caso al papa (esperando quizá - apunta Ramírez- que entre tanto muriese). El dominico escribió en efecto a Clemente VIII, pero no obtuvo respuesta. De ahí que nuevamente se dirigiese a la Santa Sede, pues le parecía que el asunto estaba tomando visos heréticos.

Tratándose, en efecto, de una controversia de tipo teológico, el Tribunal del Santo Oficio de México intervino. El 5 de noviembre de 1605 expidió patente de comisario del Santo Tribunal de la Fe a don Pedro de Lira, quien llegó a Guatemala el 23 de diciembre del mismo año. Para mayo de 1606 el asunto se zanjó en favor de la opinión del obispo, quien no en vano era un teólogo afamado. Por tanto, a partir de ese año se celebró con toda pompa el 15 de agosto la fiesta de la Asunción, y siete días más tarde la de la Coronación de la Virgen. ${ }^{38}$

La última de las tres cartas, redactada en latín, es posterior en apenas quince días a la primera. Este dato, aunado a que su contenido es prácticamente el mismo que el de aquélla, me hace suponer

38 Estrada, ob. cit.: 201. 
que corresponde - al menos en su mayor parte- a una traducción, lo que no es de extrañar cuando se observa que diversos papeles del Archivo Vaticano son traslados del español al italiano y de éste al latín, cuando no directamente del primero al último.

La carta se inicia con una felicitación al pontífice por su elección. ¿A quién se dirige?, es casi imposible saberlo. Muerto Clemente VIII, le sucedió en el trono pontificio León XI, quien sólo lo ocupó 28 días (1-27 abril de 1605), siendo substituido por Paulo V (1605-1621). El escueto encabezado: "Beatísimo padre", nos impide saber si el obispo americano estaba enterado ya de la segunda defunción o apenas sabía de la primera.

A lo largo del texto se repiten las quejas contra las autoridades civiles, sobre todo por su ingerencia en lo relativo a las excomuniones decretadas por el prelado, y nuevamente se hace mención al curioso asunto de la capa, que ha de irse "arrastrando por el suelo; por charcos y lodos aunque sea... de brocado, porque les parece a ellos que el llevar la falta el capellán es irreverencia contra la Audiencia Real".

El principal interés de la misiva no reside en las repetidas quejas sino en la radicalización de la postura episcopal ante el Real Patronato. En efecto, después de describir los múltiples problemas que enfrenta con los representantes del monarca español, fray Juan advierte al pontífice de los peligros que entraña el que los obispos sigan "haciendo el juramento de observar el Patronazgo Real, porque esto va en total destrucción de la jurisdicción eclesiástica, poniendo en peligro las almas y en infamia a los clérigos", quienes han de acatar órdenes reales que menoscaban su propia autoridad.

El papa no debe, por tanto, permitir, nullo pacto, que se continúe prestando tan peligroso juramento por el cual se ponen a los obispos "tan terribles gravámenes... que ningún rey pasado había impuesto a las personas eclesiásticas".

El, por su parte, parece haber tomado ya su propia resolución: si el observar tal juramento significa ir en contra de sus convicciones, "ciertamente el obispo de Guatemala, con pase y licencia de Vuestra Santidad, dejará y renunciará al obispado".

A diferencia de las cartas, el Informe, dirigido también a Clemente VIII, versa directamente sobre la situación laboral indígena. Dada su importancia decidí transcribirlo en su totalidad. 
Beatísimo Padre:

Fray Joan, obispo de Guatemala, dice que después de haber venido a Roma a besar vuestros santísimos pies y visitar personalmente los lunbraros(?) apostólicos, conforme al juramento que Vuestra Santidad le mandó hacer en las bulas de su consagración, quiso venir a la presencia de Vuestra Santidad y darle noticia del modo y manera como los visorreyes y gobernadores, que gobiernan [a] los indios en lugar de los reyes de España, disponen y trazan aquel gobierno, lo cual pasa de la manera siguiente:

Por leyes y ordenanzas de los visorreyes y gobernadores de los indios, se manda que de cada uno de los pueblos comarcanos y finítimos a las haciendas, estancias o pueblos de los españoles, vengan tantos indios a servir personalmente a los españoles. Desta manera, vienen de un pueblo cada semana 30 , de otro 40 , de otro 60 o 90, según son los pueblos mayores o menores, y por este modo se juntan todos los lunes de cada semana entre dos y tres horas e pasado medio día en un corral 600 indios, en otro que en otro [sic] mil. Vienen unos [desde] diez leguas donde tienen sus casas, hijos y mujeres. Otros vienen de 20 leguas y en el Pirú de 40 y más.

Estos indios traen consigo lo que han de comer desde que salen de sus casas hasta que vuelven a éstas, porque los españoles no dan de comer a los indios en todo el tiempo que están a su servicio. En la Nueva España, después de los 8 días que han servido, les dan 4 reales, pagándoles por cada día medio real, que es allá la menor moneda que corre, con la cual no pueden comprar sólo el pan que comen, y averiguando bien la cuenta, los indios sirven de balde sin que responda jornal alguno a su servicio y trabajo; antes ponen de su casa dos reales y más, de manera que de su trabajo no llevan fruto alguno para sus casas.

En todo el tiempo que están fuera de sus casas no tienen doctrina ni la pueden tener, no oyen misa los domingos y fiestas de ordinario; házenlos trabajar días y noches y más de lo que sus fuerzas flacas pueden. Trátanlos mal de palabras y de obra llamándolos perros y diciéndoles palabras afrentosas y apaleándolos. Y lo primero que hacen en teniéndolos en su poder es desnudarlos y tomarles los vestidos como en prendas para que no se huyan. Con todo [y] esto, muchos se huyen a mitad de la semana y otros al fin, o un día antes que cumplan, porque quieren más irse a sus casas perdiendo sus vestidos y el salario que se les debe, que sufrir tan malos tratamientos.

Llaman los indios [a] este servicio personal infierno, y querrían más estar en las cárceles presos que servir a los españoles con tanta fuerza y violencia.

Cuando vienen de los pueblos traen los dos alguaciles, y los que pueden huirse se huyen y otros se esconden, y si faltan dos o tres, el juez español que se llama repartidor de indios hace que los alguaciles sirvan por los que faltan con toda fuerza y 
violencia. Y no contentos con esto, envía[n] por los gobernadores y alcaldes ordinarios de los indios y los meten en la cárcel y lleva[n] grandes penas sin haber en ellos culpa alguna.

A estos lugares donde se juntan 600 o 700 o mil indios, acuden ciertos hombres españoles que se llaman jueces repartidores, y éstos reparten los indios dando a un español 10, a otro 14, a otro 20 , como le parece, y también a quien mejor se lo paga, y hay repartidor que recibe 50 pesos, porque se obliga a dar cada semana 10 o 20 indios. De manera que ansí reparte los indios como si fuesen esclavos y mancipios.

Estos repartidores son los más crueles tiranos que los indios pueden tener, porque como son tan interesados y de cada indio que reparten tienen un certum quid que les vale cada año más de mil pesos, piden con grandísimo rigor el número de indios que está señalado y por esta causa los indios no tienen seguro ni hora en todo el año; porque los alguaciles, porque no les falten indios, echan mano del primero que topan, y no les vale decir que la semana de pasada sirvió, ni que tiene la mujer enferma o recién parida, ni que ha menester segar sus panes. Ninguna excusa le admiten, ni causa razonable; todo lo ha de dejar y ha de ir a servir aunque todo se le pierda. Desta manera son tratados aquí los cristianos recién convertidos; aquestas plantas nuevas en la fe, dándoles grandísimas ocasiones para arrepentirse en haber recibido el bautismo, pues son tan maltratados. Y los infieles no osan recibir nuestra sagrada fe y religión cristiana por miedo que tienen muy probable de venir en otra tan miserable servidumbre.

Los reyes de España nunca han tenido tan clara relación de lo que hacen sus visorreyes como ésta, y después que la han tenido han procurado remediar estos males, pero algunos de los consejeros de Indias son muy interesados y por todas las vías que pueden, procuran dilatar y diferir estos remedios.

En 22 de febrero del año pasado de 1600 se tuvo un Consejo donde se hallaron el presidente de indios y el confesor de Su Majestad y los oidores del Consejo de Indias y dos maestros en teología, uno de la Orden de Predicadores [y] otro de la Orden Eremitas Sancti Augustini. Allí se determinó que no hubiese más repartidores ni repartimientos de indios de servicio personal, ni para minas ni otra labor, sino que los indios gocen de su libertad como la gozan todas las personas libres que están en Indias.

Su Santidad mandase que se pusiese en ejecución aquel decreto, y con censuras prohibiese este violento y nocivo servicio [ilegible] o que por lo menos mandase con grande rigor y censuras a todas las personas eclesiásticas, obispos, clérigos o religiosos de cualquier religión que sean, que no se sirvan en manera alguna de los indios que llaman del repartimiento, aunque se los ofrezcan $\mathrm{v}$ den los visorreyes y gobernadores, sino solamente de los indios ciue voluntariamente y sin ser forzados ni compelidos quisieran 
alquilarse y servir, y trabajar en las haciendas o casas de personas eclesiásticas. Con esto se dará principio al remedio de tantos daños como los indios y los reyes de España han recibido por estos tan injustos repartimientos o robamientos de las haciendas y libertad y vidas de tantos indios como se han consumido y acabado por este mal gobierno y tan injusto servicio personal.

Esto han procurado todos los reyes de España con muchas cédulas que sobre este caso han enviado a los visorreyes, encargándoles quitasen este servicio personal y que dejasen a los indios gozar de su libertad como los otros cristianos, pero los visorreyes y gobernadores nunca han obedecido estas cédulas reales, porque hay en las Indias muchos hombres interesados, y por hacerse ellos ricos en breve tiempo, no se les da nada porque los indios se mueran y acaben como se han acabado ya en muchas islas y se acabarán los del Pirú y Nueva España en brevísimo tiempo si Su Santidad no lo remedia. Y acabados los indios cesará la plata, y acabarse han todas las riquezas que de los indios vienen a estos reinos, además del grande escándalo e impedimento que se pone a la predicación del evangelio con estas tan grandes tiranías y opresiones de los indios, que dan voces y claman pidiendo a Dios venganza.

Sin rúbrica.

\section{Otros informes}

Aunque hasta ahora no se ha realizado una apreciación global de los escritos de Ramírez, muchos de los cuales permanecen por desgracia inéditos, la riqueza de datos contenida en los pocos que conocemos es de tal magnitud, que hace necesaria la pronta valorización del dominico como una de las figuras señeras no sóla en lo que a la protección del indígena respecta - honor que comparte con otros muchos - sino muy particularmente en lo relativo a los derechos laborales de éste.

Dadas las limitaciones de esta comunicación, me restringiré por ahora a destacar algunos aspectos de interés contenidos en los dos textos impresos de 1595 que se conservan en el Vaticano ${ }^{39}$ (aquí nominados Advertencias y Parecer), en el resumen que sobre la correspondencia episcopal hace Sherman en el artículo antes citado y en algunos escritos paleografiados y editados por Pedro Carrasco. ${ }^{40}$

${ }^{39} \mathrm{He}$ decidido emplear las copias que sobre los impresos madrileños existen en el Vaticano, pues en ellas constan correcciones y notas que no registra el material publicado por Estrada.

10 Carrasco, ob. cit., 115-160. 
Las Advertencias ${ }^{41}$ comprenden, a la manera de la época, una enumeración de "razones", en este caso nueve, por medio de las cuales se pretende comprobar la premisa inicialmente propuesta: la ilegitimidad del forzado servicio personal indígena.

El alegato se inicia invalidando la legalidad del repartimiento, institución creada - en la forma en que se observa - "sin orden y sin mandato expreso de los Reyes Católicos... [y] en fraude de la ley que el emperador Carlos V... hizo cuando mandó que los indios no fuesen esclavos, ni sirviesen a los españoles como esclavos". La responsabilidad de crear tan nefasta institución no ha de imputarse, pues, a los reyes españoles, sino a la ambición de sus representantes, coludidos con los peninsulares residentes en Indias, quienes los mal informaron y transgiversaron sus órdenes.

Una vez hecho este diplomático "descargo" de la conciencia real, el dominico describe las características del repartimiento "o guatequil [coatéquitl] o infierno, que ansí lo llaman los indios": esclavitud de facto ("que se les quitó el nombre de esclavos, pero quedaron los indios sujetos a otra más dura y pesada servidumbre"), jornal miserable por no decir nulo y aumento de cargas conforme los indios disminuyen.

La segunda razón argüida es ser tal servicio contra el Derecho Natural, que hace a todos los hombres libres, mientras que a los indios se les trata peor que esclavos, pues si a éstos sus amos les dan de comer y los visten y curan, los aborígenes americanos no obtienen nada de ello. La tercera razón alude al salario, que no es libremente concertado entre el jornalero y su empleador, sino que lo fijan arbitrariamente los gobernantes, pagándose de paso lo mismo al holgazán que al diligente.

La cuarta argumentación se basa en el precepto evangélico de no hacer a otro lo que uno no quiera para sí mismo; precepto que violan los españoles al obligar al indio a realizar trabajos bajo condiciones que ellos nunca aceptarían. La quinta presenta iguales fundamentos: la suavidad del yugo de Cristo se ha tornado para los indígenas en carga insoportable. Comparada con la esclavitud de los israelitas en Egipto, la de los americanos es peor: éstos son esclavos en su propia tierra.

$\mathrm{Si}$ las tres primeras razones esgrimidas se sustentan en ser el repartimiento una violación al Derecho Natural y las dos siguientes

41 Se conservan en la sección Segretaria Stato, Nunziature Diverse 264, f $37-42$. 
en transgredir el Derecho Divino Evangélico, la sexta y la séptima asientan ser dicha institución contraria al Derecho Positivo Eclesiástico, tanto por no observar las declaraciones de Paulo III sobre los indios "que no pueden ni deben ser privados ni despojados de sus haciendas, mandos ni señoríos, ni de su libertad; ni antes de recibir el bautismo ni después de haberlo recibido", como por violar las obligaciones cristianas a que se sujetaron los monarcas españoles a cambio del Patronazgo Real. ${ }^{42}$

Contra el Derecho Civil y Eclesiástico van las "tiránicas angarias y superangarias que todos los doctores teólogos y juristas, utriusque iuris, afirman ser exacciones injustas y aflictivas de los súbditos..." que dan origen a la razón octava.

La última razón expuesta afirma que el repartimiento va contra la Sagrada Escritura, donde "se condena el oprimir a los pobres, a las viudas, a los huérfanos, y el no dar el justo salario al obrero, y todo esto se halla en estos repartimientos".

"Presupuesta ya esta verdad: que todos los repartimientos son injustos y contra todo Derecho Natural Evangélico y De las Gentes", pasa el religioso a describir algunos de los agravios que por ellos reciben los indios: la pérdida de la libertad, malos tratamientos, injusto jornal, vejaciones a las mujeres y sus maridos, pérdida de las cosechas y "otros muchos... reciben los indios vasallos de la Majestad Real, que le pagan tributo; tan encomendados del papa Alejandro VI a la protección y amparo de los Reyes Católicos de España". Tras la argumentación de fray Juan, la junta de dominicos que revisó el documento, declaraba en Madrid el diez de octubre de 1595:

"Estos repartimientos son injustos y ajenos de toda piedad cristiana, y... el rey tiene obligación precisa y estrechísima de mandarlos quitar de todo punto".

Los puntos señalados en el segundo documento, el Parecer, ${ }^{43}$ coinciden en muchos aspectos con el dictamen anterior como era de esperar. Pueden resumirse de la siguiente manera:

El repartimiento de indios es injusto, ya que éstos eran libres antes de pasar a depender de la Corona, y tal libertad sigue no sólo

12 "Este servicio personal es realmente contra el Patronazgo Real, el cual obliga estrechísimamente a los reyes de España a que miren por los indios y los defiendan y amparen, y no permitan que sean agraviados ni molestados ni oprimidos por los españoles. Esto consta por la bula del papa Alejandro VI...".

\$3 Segretaria Stato, Nunziature Diverse 264, f 43-46v. 
siendo vigente, sino que se ha visto acrecentada al convertirse a la fe católica.

El dominio de los reyes sobre los indios es justo en tanto que les corresponde encaminar a éstos a la vida eterna. Incluso superior, por ello, al que tienen sobre los peninsulares, que es sólo temporal: De ahí se sigue que

el principal intento y fin que los reyes deben tener en el gobierno de los:indios es el bien temporal y espiritual de los mismos, y no el traer de las Indias mucho oro, ni plata, ni otras comodidades temporales, porque todo esto es como accesorio y menos principal... Este fundamento consta porque los indios no vinieron a poder de los Reyes Católicos por vía de guerra justa, que nunca la pudo haber ni la hubo, sino por sola la concesión del papa Alejandro VI".

Los indios no tienen ninguna obligación de sustentar "a todos cuantos españoles, italianos y franceses pasan a las Indias y moran allá", pues ellos no van por el bien temporal o espiritual de los primeros, sino buscando sus propios intereses,

De manera que la violencia que se les hace en estos que llaman repartimientos no sirve a la necesidad de la República, sino a la codicia desordenada e insaciable de los que quieren hacerse ricos en brevísimo tiempo y vivir holgando con el sudor ajeno y trabajo de los pobres indios, que tan poco les cuesta, pues lo aprecian con la menor moneda que corre en la República. Y como dicen: a tuerto o a derecho, nuestra casa hasta el techo.

Los indios tampoco tienen mayor obligación que los españoles, mestizos, mulatos o negros libres, de acudir a las obras públicas, ¿y por qué sólo los indios han de pagar tributo y no "los mestizos, ni mulatos, ni negros libres, ni españoles, italianos, griegos ni portugueses, holgazanes y vagamundos de los cuales hay muchos en todas las Indias"?

Por tanto, concluye:

1. Los repartimientos son injustos, en contra de la ley evangélica, y "estorbo manifiesto para que no aprovechen en la religión cristiana los indios que la han recibido, y para que los que no están convertidos no osen recibir el bautismo". De aquí se desprende un obvio corolario donde se advierte el inicio de su posterior actitud 
sobre el Real Patronato: "en mucho es defraudada la intención santa que tuvo el papa Alejandro VI cuando concedió las Indias Occidentales a los Reyes Católicos".

2. El rey está obligado a terminar con tal institución.

3. Es igualmente obligatoria la "restitución de los daños que los indios reciben en sus propias haciendas y vida", el suprimir la imposición de cargos que sólo han de cumplir los naturales y otras arbitrariedades.

Gracias a este repartimiento se cometen, pues, cuatro pecados: opresión de pobres, defraudación del jornal del obrero, homicidio (ya que a causa del excesivo trabajo los indios perecen) y "el pecado extraordinario" (la sodomía, propiciada por el amontonar en corrales a los indios desnudos).

Como en el Informe dirigido al papa, el texto al Consejo de Indias concluye advirtiendo la posible extinción de los indígenas a causa de tan brutales agravios, "los cuales no se podrán atajar sino es arrancando esta mala y perversa raíz de la fuerza y violencia que se hace en estos repartimientos".

Las catorce relaciones localizadas por Sherman en el Archivo General de Indias, son sin duda algunos de los documentos más ricos que poseemos sobre la situación laboral indígena en la Guatemala de los albores del siglo XVII. En ellos se destacan, una por una, las diferentes tareas que se obligaba a desempeñar a los naturales y las variadas formas en que prácticamente todas y cada una de las autoridades los explotaban; en particular los alcaldes mayores, quienes venían al Nuevo Mundo "como perros hambrientos a beber la sangre de los indios".

Tequitines (jornaleros por semana); teupantlacas (indios músicos y cantores); indias empleadas como sirvientas sin salario, que no pocas veces terminaban como mancebas de los patrones o sus mayordomos; viudas a las que se obligaba a seguir pagando el tributo de sus maridos difuntos; artesanos defraudados en su jornal; doncellas plagiadas; tlatoques (principales) empleados como viles enganchadores de jornaleros, que además eran castigados con multas, cárcel o azotes públicos en las nalgas - que los desacreditaban ante los maceguales - cuando no lograban reunir el número de trabajadores pedido; indias molenderas (tezintines) sin paga; indios que eran obligados a trabajar en la casa del patrón cuando iban a co. brar su salario y otros tipos de indígenas explotados desfilan en la 
correspondencia del obispo desplegando ante nuestros ojos la precaria situación laboral de los naturales; situación que el prelado avala en ocasiones con testimonios de las propias autoridades indígenas.

Junto a ello, las quejas repetidas del fraile contra los gobernantes, quienes no sólo defraudaban a los aborígenes en su jornal, sino que les obligaban a mantenerlos durante sus visitas, con frecuencia innecesarias, a los pueblos (aprovechando de paso para engordar a sus animales y revender a los indios mercancías que en otros pueblos habían comprado a muy bajo precio); que contribuían a arruinar las sementeras al obligar a los campesinos a abandonar sus caseríos para asalariarse; que hacían devenir tierras tributarias las que eran propiedades comunales; aumentaban los tributos haciendo en ocasiones que los hijos menores heredaran deudas fiscales de sus padres, o convirtiendo en obligación tributaria la paga de "limosnas" a la Corona, todo lo cual orillaba a los indios a vender no sólo sus escasos excedentes y pertenencias, sino incluso a sus propios hijos o los cuerpos de sus mujeres a mestizos y mulatos. ${ }^{44}$

Una y otra vez insiste el prelado en que uno de los mayores males en la provincia era el excesivo número de autoridades locales, mismas que propone substituir por administradores indios, cuya capacidad y honradez son probadas, además de que gozan del reconocimiento de sus coterráneos. Con ello se evitarían, amén de los despojos y arbitrariedades, los continuos problemas por jurisdicciones sobrepuestas que desembocan en repetición de pagos por parte de los indígenas y un mayor gasto para el erario real.45

Como apunta Sherman, aun tomando en cuenta la tradicional rivalidad entre seglares y religiosos, la débil defensa que ante tan devastadoras acusaciones hizo la Audiencia, deja entrever la gran dosis de verdad que contenían. . $^{6}$

Los documentos publicados por Pedro Carrasco, algunos de los cuales sirvieron a Sherman, se sitúan entre 1603 y 1604 . Destaca entre ellos la Relación de este último año, ${ }^{47}$ largo texto donde se

14 Sobre la tributación en Guatemala y sus particularidades, véase Carrasco, ob. cit.: $149-151$ y 159.

ss Una interesante descripción de la forma en que tales autoridades se superponían, por supuesto en perjuicio de los indios, se encuentra en Carrasco, ob. cit.: 156-157.

46 Sherman, ob. cit.: 27.

47 El título completo es Relación hecha por el obispo fray... sobre los agravios que recibian los indios de Guatemala, y causas de su disminución (Carrasco, ob. cit.: 115-143). 
enumeran las vejaciones sufridas por los indígenas del obispado. Dado que muchos de los casos citados son semejantes a los antes descritos, señalaré sólo las innovaciones.

Fray Juan, siguiendo el método escolástico, apunta al inicio las razones que "hombres doctos y personas de experiencia" han postulado como posibles causas de la disminución del número de indígenas en la zona, para después irlas refutando. Entre ellas se cuentan la idolatría de los americanos y los inescrutables designios divinos (¿qué acaso hayan decidido terminar con los indios una vez evangelizados?).

A la primera de tales causas el obispo contrapone su propia experiencia como diocesano: "muchos años ha que ni rastro de la idolatría no se ha hallado entre estos naturales", "el santo evangelio se ha arraigado en todas las provincias de la Nueva España y éstas, de que ha resultado mucho ejemplo y fruto en todos los naturales" $;^{48}$ ante la segunda expone su convicción de que la prédica del evangelio lleva aparejada el aumento de los pueblos, sobre todo en aquellos como el indígena donde, antes de recibirse la luz de la fe, se castigaban con la muerte aun los delitos más débiles.

Para él, la causa del deterioro demográfico es clara: disminuyen en número los pueblos cercanos a asientos de españoles, como lo demuestra el caso de Guatemala. Para sustentar su afirmación, describe uno a uno los atropellos que sufren los poblados a manos de jueces mayores, ordinarios, encomenderos, "quebrantagüesos" ("mercaderejos de poco caudal"), jueces de milpa y otros españoles que esquilman a los indios en forma tal que lo que extraña al obispo no es que los naturales disminuyan, sino que aún sobrevivan algunos.

Ramírez emplea, en apoyo de su alegato, la cita continua de casos por él conocidos: indios muertos de hambre, de fatiga y hasta de tristeza, o que se suicidaban desesperados; pueblos que encontró vacíos al visitarlos por estar todos los indios cumpliendo tareas del repartimiento; mujeres violadas; naturales empobrecidos de tanto pagar tributos, condenaciones y costas; otros que huían a las mon-

$48 \mathrm{La}$ validez de tal aseveración resulta hoy muy cuestionable; baste recordar que las actividades idolátricas indígenas durante el tiempo de Ramírez (incluso al parecer conocidas del obispo) son mencionadas por Vázquez (1944:318-19). Una centuria después ocurrirían las famosas misiones de Margíl, que pusieron al descubierto prácticas no muy ortodoxas en las provincias de Guatemala (Sáenz de Santa María, 1981). 
tañas por evadir los pagos; niños que morían al verse privados de los cuidados maternos, y otros casos por el estilo.

La continua acusación que hacen los españoles a los indios de ser brutos o inútiles, es contestada por el prelado con cierta gracia: "es inhumanidad culpar a estos pobres y llamarles brutos y bárbaros, y pues no han estudiado las artes liberales y matemáticas, no citán obligados a saberlas; que quizá a muchos bachilleres se los lleva el Diablo y éstos, con su poco talento, les roban el Cielo". Lastimosa por cierta es en cambio la descripción sobre una pareja de indios que nos legó Ramírez, y aunque larga, no puedo vencer la tentación de citarla. ${ }^{49}$

Quien pudiera, si posible fuese, para prueba de todo lo dicho, poner en el sacro palacio y curia romana una casa de un indio natural de estas provincias, y en ella el indio y su mujer con cuanto en ella tienen, y dijese a Su Santidad:

Señor, ésta es una casa de un indio hijo de la Iglesia y cristiano de las Indias, y luego le sacase de la misma manera que anda en estas partes, que es con una camisilla y unos zaragüelejos viejos y pobres, descalzo y destocado, y dijese: Señor, éste es un vasallo de Su Majestad; que le da cada año un real de tributo. Éste, Señor, da también cada año a un encomendero doce o catorce o más reales de tributo. Éste da de comer al alcalde mayor cuando está en su pueblo, o a otro cualquier juez, de gracia y aún por fuerza. Este sirve a los alcaldes ordinarios y a los vecinos de tequitine, haciéndoles sus milpas y demás gran. gerías. Éste, cuando le hacen alcalde en su pueblo, por no cumplir con la presteza que quieren sus mandamientos, por no poder, le llevan preso y le llevan penas y condenaciones y le hacen otras muchas molestias. Éste, cuando más descuidado está, viene a su pueblo un correo con un despacho y le hace ir trotando a pie, con una maleta a cuestas, cinco y seis leguas y le hace volver sin paga y maltratado. Este hace las milpas, cuando le dejan, suyas y de su comunidad. Êste, cuando está el cura en su pueblo, le da de comer.

Finalmente podemos decir que éste es un pobre hombre afligido de todos cuatro costados, que [aun] cuando fuera de acero se había de cansar o gastar.

Pues tras esto sacasen a una pobre india, su mujer, con un trapillo por naguas y otro por güipil y dijesen: Señor, del trabajo ésta lleva la peor parte, ésta muele, ésta teje la manta que se ha de dar al encomendero; ésta deshierba, siembra, y [re]coge

49 Esta cita, como las anteriores, se tomó de la Relación publicada por Carrasco, únicamente se modernizó el texto y se corrigieron algunos errores de transcripción. 
sus milpas con su marido, y algunas veces se la quitan al pobre de su marido para que sirva [a] algún español, y se la llevan contra su voluntad seis y ocho leguas, dejando a este pobre hombre solo, sin quien le remedie sus necesidades y trabajos.

Pues Señor, falta más que ver, entren dentro de su casa y vean las alhajas, caudal y riqueza de estos pobres hombres. Hallarán que la cama es un cañizo y encima un cuerezuelo de venado - y aún algunos no lo tienen - y la frazada con que se arropan es lo que traen encima. Esto les es siempre y en todo tiempo cobija y les sirve después de mortaja. Allí dentro tienen una pedrezuela con que muelen su maíz, cuatro ollas viejas, otras tantas jícaras o vasijas en que beben, un medio machete o hachuela. Éste es todo el caudal de este pobre hombre afligido, pues esto pasa y esto tiene este cuitado que aquí ve Vuestra Santidad.

¿Pues habrá habido gente y nación en el mundo que tanta pobreza y miseria pasen, quizá sí, pero que lo sufran con tanta paciencia todos en general y con tantos agravios, quizá no. Que hayan sufrido muchos agravios, quizá sí, pero que hayan sufrido tantos y tan enormes, quizá no. Que los que no les han obligación les maltraten, quizá si, pero que los que los habían de íavorecer y amparar los traten tan mal, quizá no.

Los remedios propuestos para acabar con tal situación son varios: instalar en cada ciudad o villa un defensor de indios; quitar o al menos cambiar a los alcaldes mayores; disminuir el poder que detentan los alcaldes ordinarios; quitar la "tácita o por mejor decir explícita" jurisdicción que sobre los indios tienen los encomederos; regular el trabajo indígena y hacer una tasación justa de los tributos o, mejor aún, destituir a las autoridades y emplear lo que se gasta en sus salarios para cubrir parte de las obvenciones indígenas.

\section{Notas finales}

Resulta interesante destacar cómo la lucha de fray Juan se dio a varios niveles: teórico con sus escritos, práctico en su actuación

50 En el segundo documento transcrito por Carrasco (ob. cit.: 151), fechado el 10 de marzo de 1603, el diocesano apunta: "Y estos jueces de ordinario son gente vil y apocada. Con la vara de justicia que llevan se hacen mercadere y tratantes rom '. nn in ordinario los alcaldes mayores y corregidores, los cuales todos Vuestra Majestad debería quitar de toda esta provincia, porque sin ellos estaría mejor gobernada". 
como religioso y prelado $;^{51}$ tratando de influir sobre el superior de su Orden, ${ }^{52}$ sobre la Corona (lo que en ocasiones logró ${ }^{53}$ ) y sobre el Papado, demandando de éste que utilizase tanto su poder espiritual como el temporal.

Es sin duda en este último rubro donde se localiza la originalidad de la actitud del dominico, pues si bien parece desprenderse de sus escritos que al principio confió en que la intervención ante la Corte podría aliviar la situación indígena, sus posteriores relaciones dejan entrever su desengaño. Por ello, insta al pontífice a despojar a los monarcas españoles de los derechos obtenidos gracias al Real Patronato; prerrogativas a las que ya no son merecedores dado el descuido que han tenido para proveer a los indios de bienes temporales y espirituales.

Sus argumentos son también, como hemos visto, variados, y los fundamenta tanto en Reales Cédulas como en citas bíblicas y de los Padres de la Iglesia; en testimonios indígenas, de doctrineros de la zona o de religiosos bien conocidos como Las Casas. Todo ello entremezclado con sus propias experiencias.

Las largas denuncias son una y otra vez las mismas, como apuntara Sherman a propósito de la correspondencia, ${ }^{54}$ pero ello no es de extrañar. Observando con detenimiento los diversos escritos nos damos cuenta de que si las bases doctrinarias y legales son las mismas, los ejemplos varían. Ello da buena cuenta de lo generalizado de la explotación. ${ }^{55}$ La repetición de idénticas denuncias a

51 Gracias a la intervención del diocesano, la Audiencia decidió elevar el salario. Empero, el aumento fue tan bajo, que Ramírez continuó con sus críticas (Sherman, ob. cit.: 16).

$52 \mathrm{El}$ texto impreso de la provisión que tras las denuncias de Ramírez dio el superior de la Orden de Predicadores, prohibiendo a los frailes el empleo de indios de repartimiento consta en el Archivo Vaticano, Segretaria Stato, Nunziature Diverse 264, f 70.

53 Sobre lo obtenido del Consejo de Indias en vida del obispo véase Remesal, ob. cit.: 1869. En 1610, muerto ya el prelado, la Corona seguía basándose en sus denuncias para ordenar a la Audiencia de Guatemala que regulase "los inconvenientes grandes que resultan de los muchos jueces que hay en los pueblos de indios" (Archivo General de Centroamérica, Reales Cédulas, A1 23, 1514, f 179).

54 Sherman, ob. cit.: 5 .

55 Los ejemplos corresponden tanto a casos ocurridos en Nicaragua y el Salvador (que entonces comprendía la hoy hondureña región de la Chuluteca), como a las diversas provincias de Guatemala (excluido Chiapas). Asimismo, se refieren hechos de la Mixteca y la provincia dominica de México e incluso en ocasiones del Perú, información que probablemente obtuvo Ramírez de 
lo largo de todo su periodo como obispo nos habla, por otra parte, de la continuidad de la situación.

Al igual que sus armas, sus blancos son diversos -alguaciles, jueces, encomenderos, corregidores, mercaderes- pero el objetivo es siempre el mismo: lograr una vida digna para el indio. Y si bien centra su obra en el aspecto laboral, su doctrina lleva implícito un cambio total. No sólo pide salarios justos para el indígena, sino que se le restituyan sus bienes. Postula su derecho a la contratación libre, a elegir sus propias autoridades, a instruirse en la fe, a optar al sacerdocio, a permanecer trabajando pacíficamente en su pueblo, a comerciar, a detentar las mismas prebendas que los "extranjeros" en la tierra, a educarse, a desposar a quien quiera, a engendrar, a cuidar de sus hijos. En suma "restituir a los indios su entera libertad para que gozen de ella".

Múltiples son pues, las enseñanzas posibles de rescatar en la vida y obra de Ramírez; imposible el hacerlo en los breves límites de este artículo. Baste por ahora señalar la urgente necesidad de em. prender tal trabajo si se pretende obtener y proporcionar una visión sincrónica, que permita el posterior análisis diacrónico de la situación laboral del indígena maya asentado en tierras guatemaltecas.

Sólo ello posibilitará, como deseaba y esperaba el dominico, el "volver por la verdad". Una verdad que nos permita a la vez el proporcionar a su obra la justa dimensión histórica que merece, y adoptar una actitud crítica por científica, y apasionada por consciente - como la suya - ante la dramática situación que hoy viven esos mismos indígenas, enfrentados nuevamente a gobernantes que, en un sentido aún más real que el postulado por fray Juan, pretenden continuar, "como perros hambrientos, a beber la sangre de los indios".

algún miembro del séquito del entonces presidente de la Audiencia, don Alonso Criado de Castilla (carta al rey del 20 de marzo de 1604. Consta en Carrasco, ob. cit.: 159).

\section{AUTORES CITADOS}

ARRóniz, OTHóN

1979 Teatro de evangelización en Nueva España, Instituto de InCarrasgo, Pedro vestigaciones Filológicas, UNAM, México.

1982 Sobre los indios de Guatemala, Seminario de Integración Social 
Guatemalteca No. 42, Editorial José de Pineda Ibarra, Guatemala, C.A.

Estrada Monroy, Agustín

1973 Datos para la historia de la Iglesia en Guatemala, v I, Socie-

Gavarrete, JuAN dad de Geografía e Historia de Guatemala, Guatemala, G.A.

1980 Anales para la historia de Guatemala 1497-1811, Editorial José de Pineda Ibarra, Ministerio de Educación, Guatemala.

Juarros, Domingo

1981 Compendio de la historia de la ciudad de Guatemala, Editorial Piedra Santa, Guatemala.

MacLeod, Murdo J.

1976 "Algunos aspectos de la presencia lascasiana en Centroamérica", Fray Bartolomé de Las Casas en Hispanoamérica, Memorias del primer simposio internacional de lascasistas, p.

Milla, José 26-41, Gobierno del Estado de Chiapas, México.

1963 Historia de la América Central, 3a. edición, Editorial José de Pineda Ibarra, Guatemala, C.A.

Núñez de la Vega, Francisco

En prensa Constituciones Diocesanas del obispado de Chiapas (1702), Edición crítica de María del Carmen León C. y Mario Humberto Ruz, Centro de Estudios Mayas, UNAM, México.

Paz, Octavio

1982 Sor Juana Inés de la Cruz o Las trampas de la fe, Seix-Barral, Barcelona.

Recopilación de leyes de los Reinos de las Indias

1973 Ediciones de Cultura Hispánica, Madrid.

Remesal, Antonio de

1966 Historia general de las Indias Occidentales $y$ particular de la gobernación de Chiapas y Guatemala, v IV, 3a. edición, Ministerio de Educación, Editorial José de Pineda Ibarra, Guatemala, C.A.

Rodriguez Cabal, Juan

1961 "Catálogo de escritores dominicos en la Capitanía General de Guatemala", Anales, t. 34, Nos. 1-4, p. 106-167, Sociedad de Geografía e Historia de Guatemala, Guatemala.

Sáenz de Santa María, Carmelo

1981 "Una revisión etnoreligiosa de la Guatemala de 1704, según fray Antonio Margíl de Jesús", Revista de Indias, No. 165,

SGhmitz-Kallenberg, Ludovicus p. 445-497, Artes Gráficas Benzal S. A., Madrid.

1933 Hierarchia Cathólica. Medii et Recentioris Aevi, v III y IV, Sumptibus et typis Librarie Regensbergianae, Monasterii, Italia.

SHERMAN, WILLIAM L.

1968 "Abusos contra los indios de Guatemala (1602-1605). Relaciones del Obispo", Caravelle: Cahiers du Monde Hispanique et Luso-Brésilien, v II, p. 5-28, Universidad de Toulouse, Toulouse.

VÁzQUez, fray Francisco

1944 Crónica de la provincia del Santísimo Nombre de Jesús de Guatemala, de la Orden de Nuestro Seráfico Padre San Francisco, en el reino de la Nueva España, 2a, edición, v IV, Bi- 
blioteca Goathemala, v XVII, Sociedad de Geografía e HisXIMÉNEZ, FRAY FRANCISCO

1930 Historia de la provincia de San Vicente de Chiapa y Guatemala de la Orden de Predicadores, Biblioteca Goathemala, v. II, Sociedad de Geografía e Historia de Guatemala, Guatemala, C.A.

\section{DOCUMENTOS CITADOS}

\section{Archivo Secreto Vaticano}

"Camilus Caetanus, Dei \& Apostolicae Sedis gratia, Patriarcha Alexandrinus...", 5-V-1598. Segretaria Stato, Nunziature Diverse 264 , f 70 .

"Advertencia del padre fray Juan Ramírez, Maestro en Sacra Teología, sobre el servicio personal al cual son forzados y compelidos los indios de la Nueva España por los visorreyes que en nombre de su Majestad los gobiernan. Madrid, 20-X1595", Segretaria Stato, Nunziature Diverse, 264, f 37-42.

"Parecer del padre Maestro fray Juan Ramírez, de la Orden de Predicadores de Santo Domingo, sobre el servicio personal y repartimiento de los indios, dado al Consejo Real de Indias. Madrid, 20-X-1595", Segretaria Stato, Nunziature Diverse, 264, f 43-46v.

"Presentación Real de fray Joan Ramírez al obispado de Guatemala, vacante por la muerte de fray Gómez de Córdoba", Acta Camerarii, v 13, f 140.

"Fray Joannes Ramírez, episcopus guatimalensis. Mitis januari 1601", Segretaria Stato, Nunziature Diverse 264, f 51-54v.

"Lettera de fray Joannes Ramírez, O.P. Romae, 19-I-1601", $V$ isitas ad Liminam 383, Guatemala, f1-2v.

"Lettere de fray Joannes Ramírez, vescovo di Guatemala". 25, 26 de febrero y 14 de marzo. Thasisco y Santiago de Guatemala, Visitas ad Liminam 383, Guatemala, f 219-223.

Archivo General de Centroamérica

"El obispo de Guatemala, Maestro fray Juan Ramírez, por carta de 27 de julio de 1608 informó a Su Majestad de los daños y vejámenes que sufren los indios como consecuencia del excesivo número de jueces que existen en sus pueblos, por las gavelas y demás imposiciones. Su Majestad pide a la Audiencia se le informe. Aranda, 11 de septiembre de 1610", Reales Céciuias, A1 23, 1514, f 179. 